\title{
NATURAL SELECTION: THE IMPACT OF SEMANTIC IMPAIRMENT ON LEXICAL AND OBJECT DECISION
}

\author{
Timothy T. Rogers \\ MRC Cognition \& Brain Sciences Unit, Cambridge, UK \\ Matthew A. Lambon Ralph \\ University of Manchester, $U K$ \\ John R. Hodges \\ MRC Cognition E Brain Sciences Unit and Addenbrooke's Hospital, Cambridge, UK \\ Karalyn Patterson \\ MRC Cognition E Brain Sciences Unit, Cambridge, UK
}

\begin{abstract}
This study was designed to investigate the impact of semantic deficits on the recognition of words and objects as real/familiar. Two-alternative forced-choice tasks of lexical decision and object decision were each administered to a case series of patients with semantic dementia. In both tasks, the critical manipulation was whether the real word or object was more or less "natural" (i.e., typical of its domain) than the nonword or nonobject with which it was paired. For lexical decision, typicality of the words and nonwords was manipulated in terms of bigram and trigram frequencies of the letter strings. For object decision, high typicality in real and chimeric objects consisted in having only or mainly visual features that are standard for objects in that category. This manipulation of relative typicality of real and made-up stimuli exerted a dramatic influence on the patients' success in both lexical and object decision. The patients' strong tendency towards "natural selection" was further modulated by both the frequency/familiarity of the real words/objects and the degree of semantic degradation of the individual patients. This outcome is in line with the authors' model of semantic knowledge and the impact of its degradation on a wide range of cognitive behaviour.
\end{abstract}

\section{INTRODUCTION}

When normal adult humans encounter a familiar object or word, they can easily judge that it is known to them; we characterise this phenomenon by saying that they have recognised the stimulus. The mechanisms for such recognition are not, however, especially well understood, and one unre- solved question is this: Can recognition be achieved on the basis of the familiarity of structural features alone, or does semantic information about the concept contribute crucially to normal, efficient recognition of it? Phrasing the question in this manner makes it immediately apparent why neuropsychological evidence is pertinent to this issue. If there are patients who have normal ability

Correspondence should be addressed to Dr T. T. Rogers or Dr K. Patterson, MRC Cognition \& Brain Sciences Unit, 15 Chaucer Road, Cambridge CB2 2EF, UK (Email: tim.rogers@mrc-cbu.cam.ac.uk or karalyn.patterson@mrc-cbu.cam.ac.uk).

This article is lovingly and grievingly dedicated to the memory of our colleague Eleanor M. Saffran. KP had several discussions with Eleanor about the expected impact of semantic impairment on lexical decision, and had hoped to benefit from her theoretical insights and experimental wisdom in investigating this issue. This paper therefore seems a particularly apt contribution to the issue of $\mathrm{CN}$ in honour of Eleanor and her outstanding contributions to the field of cognitive neuropsychology. 
ROGERS ET AL.

to process the structural features of objects or words but lack a normal complement of knowledge about the concepts represented by such stimuli, their degree of success on tests of object or word recognition might provide telling evidence on the question.

Note that when we speak of recognition in this article, we shall always mean the term in the sense just conveyed-i.e., "it is an object or a word that I know"-rather than in the episodic, recognitionmemory sense of "I recognise this word or object as one that I encountered in an earlier phase of this experiment, or on some other specific occasion in place and time." The kind of recognition in focus here is typically measured by tests of lexical decision (LD) for words and of object decision (OD) for concrete objects, and those are the tests employed in this study.

Prevailing opinion, if there is such a thing, on the question of whether recognition depends on knowledge beyond structure seems to be that it does not. That is, most language researchers would probably say that positive lexical decisions are the result of a match between the stimulus and a stored representation corresponding to a word node or lemma that, in the processing sequence, precedes access to any semantic information about the word. For example, "...when we know what the word is, we then have access to all the information about it, such as what it means" (Harley, 1995, pp. 31-32). Likewise, most researchers concerned with object recognition have argued that positive object decisions occur when the stimulus activates a stored structural description for the known object where, once again, the structural description necessarily precedes - and indeed is a gateway to - conceptual knowledge about the object (e.g., Riddoch \& Humphreys, 1987). Some models of word and object processing, however, incorporate the assumption of automatic and functionally significant interaction between perceptual processing and conceptual knowledge, and predict that significant semantic impairment will necessarily disrupt recognition (see, for example, Plaut, 1997, and Seidenberg \& McClelland, 1989, with respect to lexical decision). The proposal of the current paper is in line with this latter position. Our hypothesis is that recognising an object or word is not the result of matching it to a structural description or a lemma, but is the result of the interactive perceptual and semantic processing of the stimulus item itself, when that item consists of properties that have been encountered together in past experience. A likely corollary of this position is that there is no need to assume the existence of item-specific representations like structural descriptions or lemmas that intervene between perceptual and semantic aspects of processing, and furthermore that there is no sharp demarcation between these aspects (Barsalou, 2003; Dixon, Bub, \& Arguin, 1997; Gloor, 1997; Smith, 2000); but the experiments presented below are addressed to the more modest question of the role of semantic knowledge in object and word recognition, and the interpretation of the results will be largely confined to this question.

The full account of our thoughts on this issue will be developed after the results have been presented, but the basis for our predictions should be presaged at least briefly here. In our view (see, for example, McClelland \& Rogers, 2003; Plaut, 1997; Plaut, McClelland, Seidenberg, \& Patterson, 1996; Rogers, Lambon Ralph, Garrard, Bozeat, McClelland, Hodges, \& Patterson, in press; Rogers \& Plaut, 2002), knowledge about orthographic word form, the visual structure of objects, and the meanings of words and objects is encoded in the brain in a network of interacting distributed representations. The interactions among different kinds of representations are governed by weighted connections, whose strengths in turn are shaped by experience, so that each processing episode influences to some degree the complete system of knowledge encoded in the network. As a consequence, the connection weights that emerge after extensive experience are jointly determined by information specific to particular items and by information general to the domain. An important general property of such networks is that they are sensitive both to the frequency with which individual stimulus items are encountered in the learning environment, and to the regularities that occur across items. Information about frequently encountered items will be more robustly 
ingrained in the weights than information about less common items; but even for infrequent exemplars, the characteristics that they share with their neighbours will be more robustly represented than will their unique or individuating features.

For example, in the orthographic domain, typical or consistent spelling patterns will tend to be robust whilst atypical ones (letter combinations that occur in few words, like the acht in yacht) will be more fragile. Apart from typicality of spelling pattern, word frequency is the most important determinant of strength. As explained in detail in Plaut et al. (1996), frequency and consistency to some extent offset one another: A word can be strongly represented and efficiently processed even if it has atypical characteristics, so long as it is frequently encountered and thus overlearned. Likewise a word can be robust even if it is rarely encountered so long as it is consistent with most of its neighbours.

Because recognition in our account arises from an interaction of perceptual and conceptual processing, these two components also offset one another to some extent. Thus recognition of written words that are either orthographically unusual or of lower frequency, and especially of words that are both inconsistent and infrequent, will rely more on a semantic contribution (Plaut, 1997). We therefore predict that a deficit of conceptual knowledge will necessarily disrupt writtenword lexical decision, but only for words with atypical orthographic structure, particularly when these are infrequent words, and increasingly so with greater semantic deterioration.

Similarly, in the visual domain, attributes that are shared across many instances of a conceptual category should be more robust to impairment than the idiosyncratic visual attributes that differentiate related items (Bozeat et al., 2003; Rogers et al., in press), as should the visual properties of very frequently encountered, familiar items. Our theoretical stance thus offers the same predictions about object decision, i.e., that it should be impaired in patients with SD but only for objects with atypical visual-object structure, particularly when these are less familiar objects, and increasingly so with greater semantic deterioration.
How does our proposal accommodate the published neuropsychological evidence that has been claimed to support the alternative position? This evidence consists of demonstrations that some patients with impaired semantic memory (or impaired access to semantic memory) can achieve scores within or at least close to the normal control range on tests of LD (e.g., Breedin, Saffran, \& Coslett, 1994; Ward, Stott, \& Parkin, 2000) or OD (e.g., Humphreys, Riddoch, \& Quinlan, 1988; Lambon Ralph \& Howard, 2000). Our account of these results in the domain of OD can be found in Rogers, Hodges, Lambon Ralph, and Patterson (2003); the line of argument in the domain of LD is precisely parallel but has not yet been published, and that is what we shall emphasise in the Introduction.

The first clue to our account derives from the fact that semantically impaired patients-more specifically, patients with semantic dementia (Hodges, Patterson, Oxbury, \& Funnell, 1992; Snowden, Goulding, \& Neary, 1989)—can apparently have almost any degree of success or failure in lexical decision. Published reports of accuracy in LD to written or spoken words range from essentially normal (Ward et al., 2000), to mildly impaired (Breedin et al., 1994; Lambon Ralph \& Howard, 2000), to mildly but increasingly impaired with semantic deterioration (Tyler \& Moss, 1998), to performance no better than chance (Moss, Tyler, Hodges, \& Patterson, 1995). As usual, these various investigations have used a substantial variety of different stimulus materials and procedures and, moreover, are all single-case studies, making it difficult to draw any general conclusions.

The second and more important clue comes from the fact that two researchers studying LD in semantically impaired patients have been clever enough to manipulate the LD experimental conditions, and have also documented performance ranging from good to poor-within a single patient. Diesfeldt (1992), in studies of case $\mathrm{BHJ}$ with semantic dementia (SD), varied the characteristics of the nonword stimuli in a yes/no written-word LD task. When the nonwords were orthographically illegal, BHJ's success at 
ROGERS ET AL.

discriminating between words and nonwords was essentially perfect $(97 \%$ correct); when the nonwords were orthographically legal, he was significantly less accurate ( $79 \%$ correct); and when the nonwords were carefully matched to the words on orthographic characteristics, his discrimination was only just above chance $(64 \%$ correct). Bub, Cancelliere, and Kertesz (1985) studied case MP, in whom a severe and unusually focal head injury had damaged the left inferior temporal lobe, yielding a profound semantic impairment that resembled a nonprogressive version of SD (see also Behrmann \& Bub, 1992; Bub, Black, Hampson, \& Kertesz, 1988; and Patterson \& Behrmann, 1997, for other studies of MP). Bub et al. (1985) varied the characteristics of both the word and nonword stimuli in a two-alternative, forced-choice, written-word LD task, and again documented a wide range of success in this single case, ranging from good (though not perfect: $85 \%$ correct) when orthographically regular words were paired with orthographically irregular nonwords (e.g., block vs. macht), to chance ( $41 \%$ correct) when regularity characterised the nonwords but not the words (e.g., yacht paired with plock).

The outcome of these two studies is exactly in line with our predictions, but an attempt at replication seemed valuable for a number of reasons. First, this phenomenon has only been demonstrated for two individual cases and with different materials/procedures; we had access to a larger group of semantically impaired patients (SD) in whom the prediction could be tested with the same set of stimulus materials and the same paradigm. Second, at least one of the two patients in whom the phenomenon has been established (MP; Bub et al., 1985) had severe semantic impairment. Her reasonable success in LD for pairs like block vs. macht obviates to some extent the concern that her poor scores in other conditions might simply reflect the fact that profound brain damage disrupts all cognitive performance; nevertheless, it would be valuable to assess the impact on lexical decision of semantic deficits over a range of severities. Third, neither Bub et al. (1985) nor Diesfeldt (1992) included word frequency as a factor to be manipulated in their selection of stimulus materials, whereas our account treats frequency as a crucial component of the story. Fourth, and perhaps most important: Assuming that we would replicate the findings of Bub et al. and Diesfeldt, we wanted to set this phenomenon into a theoretical context that would emphasise its significance and its generality.

Lexical decision data for a cohort of SD patients constitute Experiment 1, and object decision data constitute Experiment 2. In both cases-as the title of this article suggests-our hypothesis is that a degraded semantic system pushes word and object recognition towards the "natural" selection of forms that are typical of their domains, whether these correspond to real or unreal stimuli.

\section{EXPERIMENT 1: LEXICAL DECISION: THE OVER-REGULAR WORD TEST (OWT)}

\section{Methods}

\section{Participants}

Twenty-two patients with a clinical diagnosis of semantic dementia (SD) - based on both cognitive and neuroradiological criteria as outlined by Hodges et al. (1992)—participated in Experiment 1. Sixteen of these cases were identified through the Memory and Cognitive Disorders Clinic at Addenbrooke's Hospital, Cambridge, UK (under the direction of consultant neurologist, and author, JRH); the remaining six cases were recruited via clinics at either St Martin's Hospital or Royal United Hospital in Bath, UK. ${ }^{1}$ Four of the 22 patients were tested at two different time points roughly a year apart, yielding a total of 26 scores for

\footnotetext{
${ }^{1}$ We are extremely grateful to Dr R. W. Jones, St Martin's Hospital, Bath and Dr David Bateman, Royal United Hospital, Bath, for their permission to publish results from some of the patients under their care, and to Elizabeth Jefferies, Department of Experimental Psychology, University of Bristol, for collecting some of the data from the patients in Bath.
} 
the 22 patients on this test. ${ }^{2}$ Table 1 gives some basic background data on the patients. Sex, age, and scores on the Mini-Mental State Examination as a general measure of cognitive status are selfexplanatory. The next two entries in the table correspond to two tests from the semantic battery used in our research programme in Cambridge (Bozeat, Lambon Ralph, Patterson, Garrard, \& Hodges, 2000; Hodges, Graham, \& Patterson, 1995): (a) Word-Picture Matching as a test of comprehension in which, for each of the 64 concrete concepts in the battery, the patient hears the spoken name of the object and is asked to point to the corresponding picture in an array of 10 line drawings (the target plus 9 distractors), all from the same category; (b) Object Naming as a combined test of semantic knowledge and word-production ability, in which each of the 64 items is presented as a single line drawing and the patient is asked to name it. The patients in the table are ordered in terms of their Word-Picture Matching scores, from highest to lowest; these scores demonstrate a substantial range of semantic impairment, from essentially normal (control participants perform perfectly on this test) to near chance. The Object Naming scores indicate that all patients, even the least impaired (AN), had some degree of anomia, as control participants also score at ceiling on this naming task. Note that AN was something of an outlier in the range of naming ability, with all other cases more notably anomic, and many of them strikingly so.

The final entry in Table 1 gives the patients' proportions correct in reading aloud a list of 42 high-frequency words with regular spelling-sound patterns from Patterson and Hodges (1992). This reading measure is included here to establish that none of these patients had any major impairment in the basic early visual processes required for the main experimental task of interest here, writtenword lexical decision. In oral reading, all 22
Table 1. Background data for the OWT participants with semantic dementia, including each patient's sex, age, Mini-Mental State Exam score at (or very close to) the time of experimental testing, Word-Picture Matching as an assessment of comprehension, Object Naming as an assessment of semantic knowledge and word production, and proportion correct in reading words with regular spelling-sound correspondences as a measure of accuracy of letter/ word perception

\begin{tabular}{|c|c|c|c|c|c|c|}
\hline Patient & Sex & Age & $M M S E^{\mathrm{a}}$ & $\begin{array}{c}\text { Word-Pic } \\
\text { Match }^{\mathrm{b}}\end{array}$ & $\begin{array}{c}\text { Object } \\
\text { Naming }\end{array}$ & $\begin{array}{c}\text { Read } \\
\text { reg } \\
\text { words }\end{array}$ \\
\hline $\mathrm{AN}$ & $\mathrm{M}$ & 64 & 29 & .98 & .91 & 1.00 \\
\hline JP-2 & $\mathrm{M}$ & 65 & 26 & .98 & .77 & 1.00 \\
\hline LS & $\mathrm{M}$ & 60 & 26 & .98 & .56 & 1.00 \\
\hline JP-1 & $\mathrm{M}$ & 64 & 27 & .92 & .80 & 1.00 \\
\hline ATe-1 & $\mathrm{M}$ & 65 & 25 & .91 & .16 & .93 \\
\hline MG & $\mathrm{F}$ & 77 & 20 & .91 & .13 & 1.00 \\
\hline NS-1 & $\mathrm{F}$ & 68 & 24 & .89 & .20 & .90 \\
\hline MA & $\mathrm{M}$ & 63 & 29 & .89 & .20 & 1.00 \\
\hline JTh & $\mathrm{F}$ & 55 & 25 & .86 & .67 & 1.00 \\
\hline WM & $\mathrm{F}$ & 55 & 24 & .81 & .22 & 1.00 \\
\hline SJ & $\mathrm{F}$ & 60 & 23 & .80 & .17 & .88 \\
\hline DV & $\mathrm{M}$ & 64 & 21 & .77 & .27 & .98 \\
\hline $\mathrm{JC}$ & $\mathrm{M}$ & 58 & 15 & .72 & .52 & .93 \\
\hline AT & $\mathrm{M}$ & 62 & 22 & .70 & .20 & NT \\
\hline NS-2 & $\mathrm{F}$ & 69 & 25 & .66 & .13 & .86 \\
\hline $\mathrm{KH}$ & $\mathrm{M}$ & 61 & 10 & .64 & .34 & 1.00 \\
\hline BS & $\mathrm{M}$ & 68 & 25 & .63 & .45 & .95 \\
\hline EK & $\mathrm{F}$ & 60 & 26 & .61 & .27 & .95 \\
\hline $\mathrm{KI}$ & $\mathrm{M}$ & 65 & 23 & .56 & .23 & .98 \\
\hline $\mathrm{JTw}$ & $\mathrm{M}$ & 66 & 25 & .53 & .08 & .98 \\
\hline ATe-2 & $\mathrm{M}$ & 67 & 24 & .45 & .08 & NT 2nd \\
\hline GT & $\mathrm{M}$ & 71 & 22 & .42 & .17 & 1.00 \\
\hline PS & $\mathrm{F}$ & 75 & 23 & .39 & .13 & 1.00 \\
\hline $\mathrm{JG}-1$ & $\mathrm{~F}$ & 68 & 19 & .38 & .18 & 1.00 \\
\hline $\mathrm{DC}$ & $\mathrm{F}$ & 78 & 15 & .30 & .05 & NT \\
\hline JG-2 & $\mathrm{F}$ & 70 & 19 & .17 & .03 & NT 2nd \\
\hline
\end{tabular}

No reading scores $(\mathrm{NT}=$ not tested) were available for two patients (AT and DC); and for two of the four patients given the OWT lexical decision test twice (ATe-2 and JG-2), reading was tested only in conjunction with the first administration of the OWT and was not repeated the second time (NT 2nd).

aScore /30. bProportion correct /64. ${ }^{\mathrm{c} P r o p o r t i o n}$ correct /42.

\footnotetext{
${ }^{2}$ Four patients were tested twice, simply because their yearly testing rounds came about twice within the 13 or so months during which these data were collected. We include both measurements here to present a complete portrait of the data. Observations were treated as independent in statistical analyses, as the patients have progressive neurological disorders and thus can show very different patterns of performance on testing rounds separated by a long period of time (see Lambon Ralph \& Howard, 2000, for discussion).
} 
ROGERS ET AL.

patients were surface dyslexic, and thus made regularisation errors in reading aloud words with an atypical relationship between spelling pattern and pronunciation (e.g., reading pint to rhyme with "mint"). Furthermore, as Table 1 indicates, a few of the patients were less-than-perfect at reading even regular words, making mainly two types of error: (a) so-called LARC errors (legitimate alternative reading of components: Patterson, Suzuki, Wydell, \& Sasanuma, 1995), in which a regular word like hoot is pronounced like its irregular neighbours "foot" and "soot"; and (b) word substitutions (e.g., trial $\rightarrow$ "trail") of the kind made by any and every reading-impaired individual. Such word substitutions were, however, rare; and both the generally high scores for reading regular words-even in some of the most semantically impaired patients - and the other error types (regularisations of irregular words and LARC errors to regular words) are all indicative of correct letter perception/identification. It therefore seems reasonable to conclude that, if the patients reveal the predicted deficits in lexical decision, this will not be attributable to problems in correctly perceiving the target words.

With the goal of demonstrating that our prediction of "natural selection" in word recognition applies specifically to the impact of semantic impairment, we also administered the OWT not only to a group of normal control subjects $(N=11$, from the MRC-CBU subject panel) who were age- and education-matched to the SD patients, but also to a small set of neurological patients with Broca's aphasia consequent on left perisylvian lesions from cerebrovascular accidents $(N=5)$.

\section{Stimulus materials}

We constructed a two-alternative forced-choice (2AFC) written-word lexical decision test dubbed the Over-regular Word Test (OWT). The test consists of 72 pairs, each containing one real word and one nonword. In each pair, the nonword is a possible pseudohomophone of the word such that the two items of the pair could be said to have the same phonology. ${ }^{3}$ The test has two conditions $(N=$ 36 pairs in each), and the critical difference between conditions is in the orthographic "goodness" or typicality of the word relative to its nonword mate, as measured by both bigram and trigram frequencies. In condition $\mathrm{W}>\mathrm{NW}$ (e.g., grist vs. gryst), the real word is more typical of general English spelling, i.e., it has higher bigram and trigram frequencies, than the nonword. In the $\mathrm{NW}>\mathrm{W}$ condition (e.g., tryst vs. trist), this relationship is reversed, and the nonword is more orthographically typical than the real word. The stimuli in the two conditions were yoked to one another, such that (a) each $\mathrm{W}>\mathrm{NW}$ stimulus pair had a partner in the $\mathrm{NW}>\mathrm{W}$ condition that differed from it minimally (e.g., cheese/cheize was partnered with seize/seese, and node/gnode with gnome/nome), and (b) the target items in the yoked pairs were matched for frequency (e.g., cheese and seize are comparably frequent words). Thus the yoked pairs in the two conditions were as similar to one another as possible in both orthography and word frequency. All stimulus items are listed in Appendix A.

Figure 1 displays the bigram and trigram frequencies for each target word and its counterpart nonword in each of the two conditions. For each word-nonword pair, the figure shows that both bigrams and trigrams are more frequent for the words in condition $\mathrm{W}>\mathrm{NW}$, but for the nonwords in condition $\mathrm{NW}>\mathrm{W}$. Bigram and trigram frequencies were calculated from the Kucera and Francis (1967) corpus as follows. Each word in the corpus was divided into its constituent bigrams and

\footnotetext{
${ }^{3}$ Note that the nonwords are possible homophones of their word counterparts in the sense that every nonword's spelling pattern has that pronunciation in some real word(s) in the language, not necessarily in the sense that most people, if asked to pronounce the nonword in isolation, would give it a pronunciation identical to the word member of the pair. For example, the nonword gryst might be pronounced /graIst/ ("griced") by some people; we consider gryst a pseudohomophone of grist because the real word tryst has this spelling pattern and rhymes with grist. Likewise, the nonword nease might well be pronounced /niz/ ("neeze"), but we selected it as a possible homophone mate for niece on the grounds that the spelling pattern_ease has an unvoiced consonant in words like lease and grease.
} 

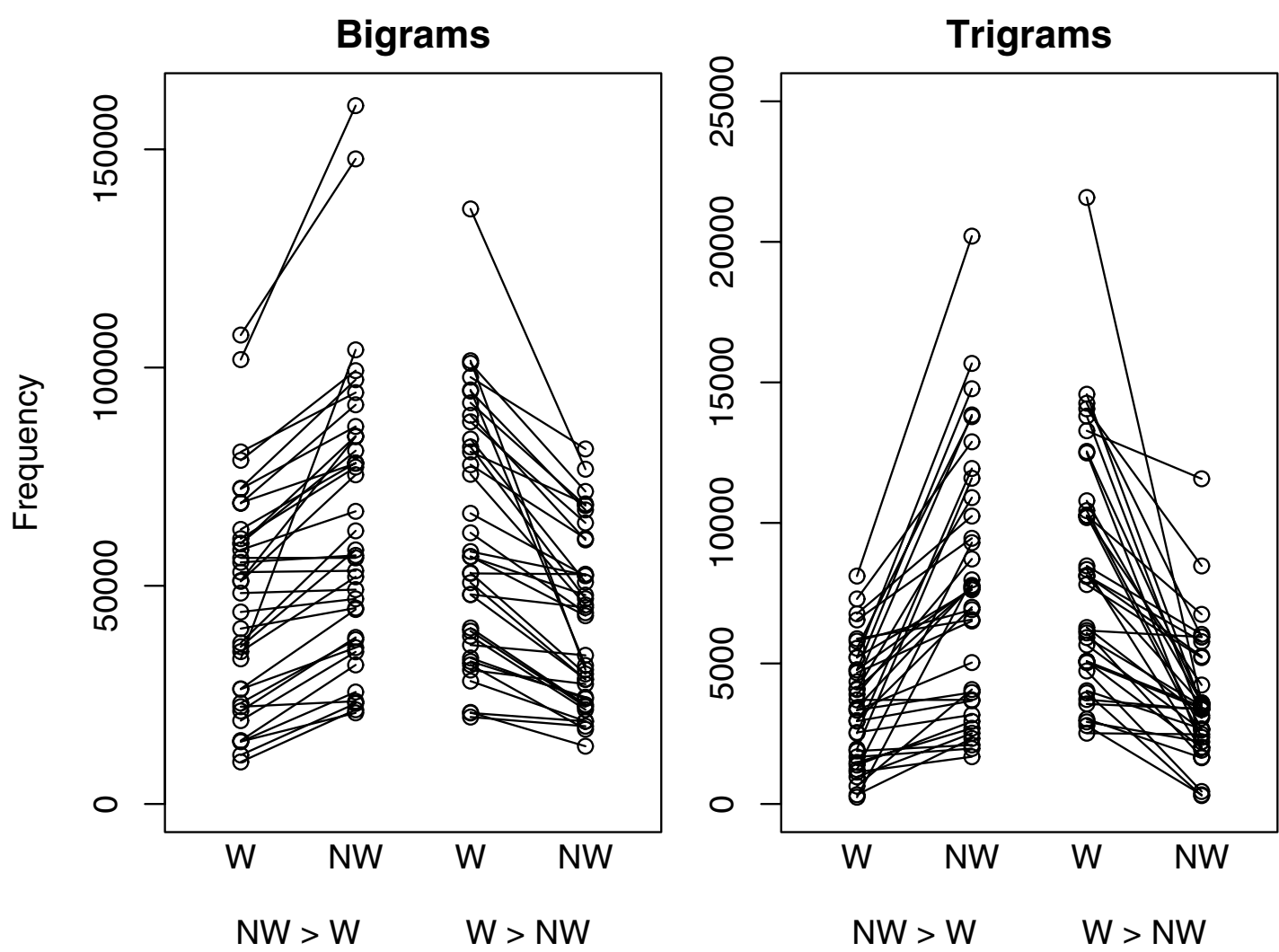

Figure 1. Bigram and trigram frequencies for the words and nonwords in the $W>N W$ and $N W>W$ conditions of the OWT lexical decision test. The lines join each real word target with its paired nonword distractor.

trigrams, and each bigram and trigram appearing in the corpus was assigned a weight equivalent to the summed frequency of the words in which it was observed. For example, the word "yacht" appears with frequency 7 in the Kucera and Francis (1967) corpus-hence this word contributed 7 to the frequency of the bigrams "ya," "ac," "ch," and "ht"; and 7 to the frequency of the trigrams "yac," "ach," and "cht." The bigram frequency for each letter string in the OWT was then calculated by summing the frequencies of its constituent bigrams; for example, the pseudo nonword "trist" received a total bigram frequency equal to the sum of the frequencies for "tr," "ri," "is," and "st." Trigram frequencies for all letter strings in the OWT were similarly calculated by summing the frequencies of the constituent trigrams. Word frequencies for the target items in the two conditions, also from Kucera and Francis, were closely matched: mean $\log$ frequency for $\mathrm{W}>\mathrm{NW}=1.59$; for $\mathrm{NW}>\mathrm{W}=1.68 ; F(1,70)=0.09, p=.77$. The items in each of the two conditions were further subdivided into two groups using a median split on the frequency of the target word, so that performance could be assessed across the 18 higher- and 18 lower-frequency items. Mean word, bigram, and trigram frequencies for the higher- and lowerfrequency items are shown in Table 2.

\section{Procedure}

The 72 experimental pairs were each printed on a separate sheet of paper, with the real word on the left in half of the pairs and on the right in the remaining half, counterbalanced for condition. 
ROGERS ET AL.

Table 2. Mean word, bigram, and trigram frequencies calculated separately for higher-frequency and lower-frequency items

\begin{tabular}{llrr}
\hline & & $W>N W$ & $N W>W$ \\
\hline Word frequency & High & 16 & 29 \\
& Low & 4 & 2 \\
Bigrams & & & \\
High frequency & Word & 63023 & 46286 \\
& Nonword & 42118 & 68682 \\
Low frequency & Word & 60312 & 47023 \\
& Nonword & 41935 & 59476 \\
Trigrams & & & \\
High frequency & Word & 8062 & 3452 \\
Low frequency & Nonword & 3650 & 8153 \\
& Word & 8274 & 5876 \\
& Nonword & 3664 & 10307 \\
\hline
\end{tabular}

The order of list presentation was randomised with the sole restriction that pairs of orthographically similar items (e.g., grist vs. gryst and tryst vs. trist) did not appear in close proximity. The instruction to participants was "Please point to the real word." In case of potential problems in comprehension of instructions by the SD patients, presentation of the 72 test pairs was preceded by 5 very easy practice pairs of words and nonwords. All of the patients, even the most severely impaired, were able to perform the task.

\section{Results and interim discussion}

Eleven age-matched control participants performed near ceiling in both conditions of the OWT. For high-frequency items, proportions correct ranged from $0.94-1.0$ with a mean of 0.99 in both conditions. For low-frequency items, proportions correct ranged from $0.82-1.0$ with a mean of 0.94 in both conditions. Controls performed slightly better for high-frequency than for lowfrequency items, but importantly, they achieved identical scores in the $\mathrm{W}>\mathrm{NW}$ and $\mathrm{NW}>\mathrm{W}$ conditions for both high- and low-frequency items.

Table 3 provides individual OWT scores from the SD group (proportion correct out of 18) for the four stimulus subsets created by crossing OWT condition $(\mathrm{W}>\mathrm{NW}$ vs. $\mathrm{NW}>\mathrm{W})$ with word frequency (higher vs. lower) for the 26 individual
Table 3. OWT performance (proportion correct out of 18) for each of the four subsets of OWT stimulus pairs, for each of 26 administrations of the test to patients with semantic dementia (SD) $(\mathrm{N}=22$ patients, 4 tested on two occasions), ordered by the patients' scores on a test of Word-Picture Matching (see Table 1), followed by mean proportions correct for the $S D$ cases, the control participants $(\mathrm{N}=$ 11) and the patients with Broca's aphasia $(\mathrm{N}=5$ )

\begin{tabular}{|c|c|c|c|c|}
\hline \multirow[b]{2}{*}{ Patient } & \multicolumn{2}{|c|}{$W>N W$} & \multicolumn{2}{|c|}{$N W>W$} \\
\hline & $\begin{array}{c}\text { Higher } \\
\text { freq }\end{array}$ & $\begin{array}{l}\text { Lower } \\
\text { freq }\end{array}$ & $\begin{array}{c}\text { Higher } \\
\text { freq }\end{array}$ & $\begin{array}{c}\text { Lower } \\
\text { freq }\end{array}$ \\
\hline $\mathrm{AN}$ & .78 & .89 & .83 & .78 \\
\hline JP-2 & .94 & .94 & .83 & .39 \\
\hline $\mathrm{LS}$ & .83 & 1.00 & .94 & .83 \\
\hline JP-1 & .83 & .83 & .78 & .33 \\
\hline ATe-1 & .78 & .94 & .89 & .44 \\
\hline MG & .94 & .83 & 1.00 & .89 \\
\hline NS-1 & .61 & .72 & .78 & .61 \\
\hline MA & .83 & .89 & .78 & .39 \\
\hline $\mathrm{JTh}$ & 1.00 & 1.00 & .89 & .44 \\
\hline WM & .67 & .78 & .61 & .56 \\
\hline SJ & .83 & .89 & .94 & .56 \\
\hline DV & .94 & 1.00 & .83 & .50 \\
\hline $\mathrm{JC}$ & .78 & .78 & .67 & .50 \\
\hline AT & .94 & .67 & .61 & .22 \\
\hline NS-2 & .78 & .89 & .78 & .33 \\
\hline $\mathrm{KH}$ & .94 & .78 & .22 & .22 \\
\hline BS & .83 & .78 & .89 & .50 \\
\hline EK & .83 & .78 & .39 & .28 \\
\hline $\mathrm{KI}$ & .94 & .94 & .72 & .17 \\
\hline $\mathrm{JTw}$ & .83 & .78 & .78 & .44 \\
\hline ATe-2 & .72 & .94 & .56 & .28 \\
\hline GT & .72 & .83 & .61 & .56 \\
\hline PS & .94 & .89 & .83 & .50 \\
\hline JG-1 & .89 & .94 & .78 & .61 \\
\hline $\mathrm{DC}$ & .94 & .94 & .56 & .06 \\
\hline JG-2 & .78 & .94 & .50 & .28 \\
\hline $\mathrm{SD}$ mean & .84 & .87 & .74 & .46 \\
\hline Control mean & .99 & .96 & .99 & .96 \\
\hline Broca mean & .87 & .69 & .81 & .70 \\
\hline
\end{tabular}

administrations of the test to SD patients. As in Table 1, the patients are ordered by their scores, from highest to lowest, on the word-to-picture matching task from our semantic battery as a measure of degree of semantic deficit. Following the individual-SD OWT scores in Table 3 are the mean proportions correct for each condition for (a) the SD patients, (b) the control participants, and (c) the patients with Broca's aphasia. 
Figure 2 displays the OWT results for the SD patients by condition on all items and also split by higher vs. lower frequency. A repeated-measures ANOVA on these results yielded a significant main effect of condition, $\mathrm{W}>\mathrm{NW}$ vs. $\mathrm{NW}>\mathrm{W}$, $F(1,25)=58.0, p<.001$; a significant main effect of word frequency, higher vs. lower, $F(1,25)=$ $40.1, p<.001$; and most importantly, a significant interaction between these two factors, $F(1,25)=$ $48.4, p<.001$.

Figure 3 displays the OWT results as mean proportions correct (with 95\% confidence intervals) on the four OWT stimulus subsets but also divided into two SD severity subgroups: OWT performance associated with the 13 best scores on the WPM task (range 0.98-0.72) vs. those associated with the 13 worst WPM scores (range $0.70-0.17$ ). To determine how the severity of semantic impairment interacts with the effects described above, we added this factor (milder vs. more severe impairment, as assessed by a median split on wordpicture matching) to the repeated-measures ANOVA described above. As before, the main effects of word frequency, $F(1,24)=82.4, p<.001$, and stimulus type, $F(1,24)=39.8, p<.001$, were reliable, as was their interaction, $F(1,24)=46.8$, $p<.001$. The main effect of severity was also significant, $F(1,24)=10.7, p<.004$, and this effect interacted reliably with word frequency, $F(1,24)=$ 11.6, $p<.003$, but not stimulus type, $F(1,24)=$ 0.85 , n.s.

The results in Figure 3 are simple to describe and constitute an excellent match to our prediction for LD performance in semantically impaired patients. So long as the words in this 2AFC LD task had more typical orthographic structure than the nonwords $(\mathrm{W}>\mathrm{NW})$, performance was good (though a little below the control range for pairs containing higher-frequency words) and insensitive to both word frequency and degree of semantic degradation. When the nonword members of the pairs were more typical of English orthography than the words, on the other hand, OWT scores were high only when the two other factors affecting performance (word frequency and patient severity) were favourable (high-frequency words
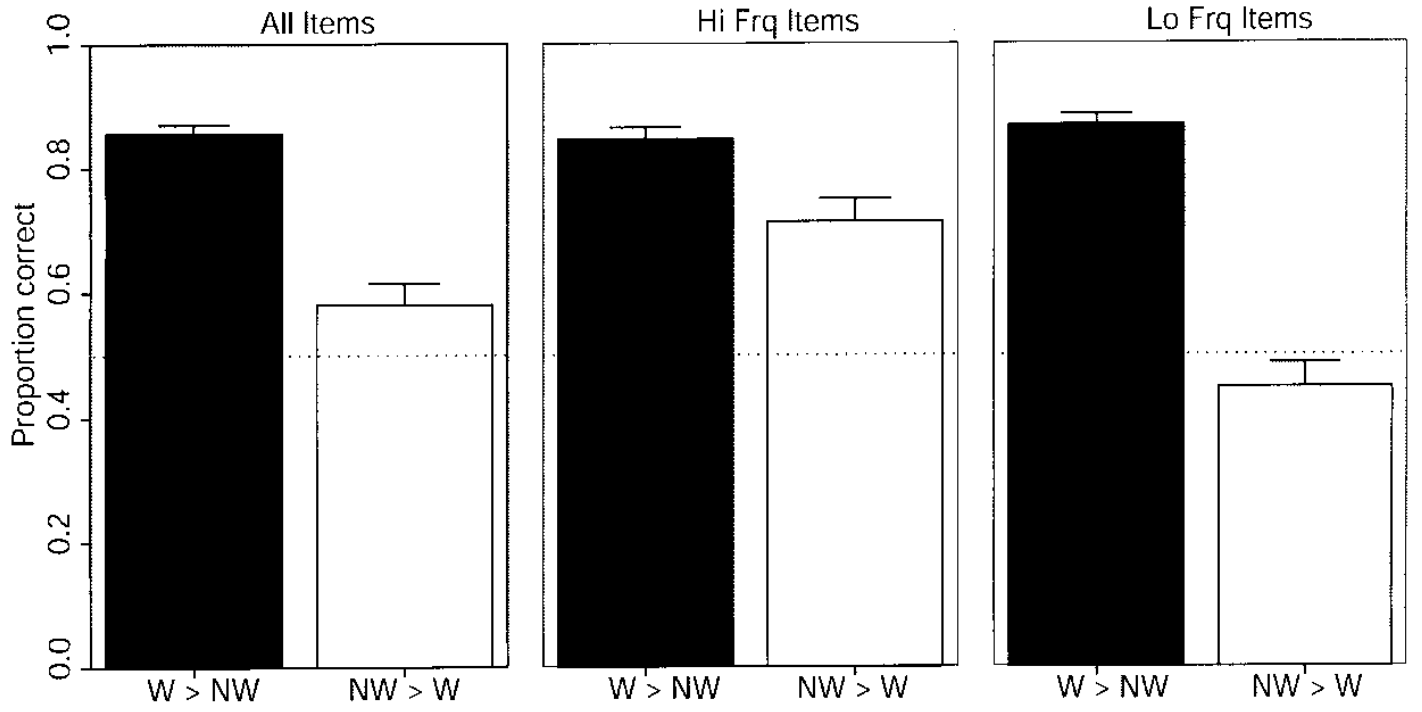

Figure 2. Average performance for the patients with semantic dementia on the OWT, first as a contrast between all items in each condition $(W>N W$ and $N W>W)$ and then divided into higher-and lower-frequency word targets. The fine dotted line at 0.5 on the $Y$ axis indicates chance performance. Error bars indicate the standard error of the mean. 
ROGERS ET AL.

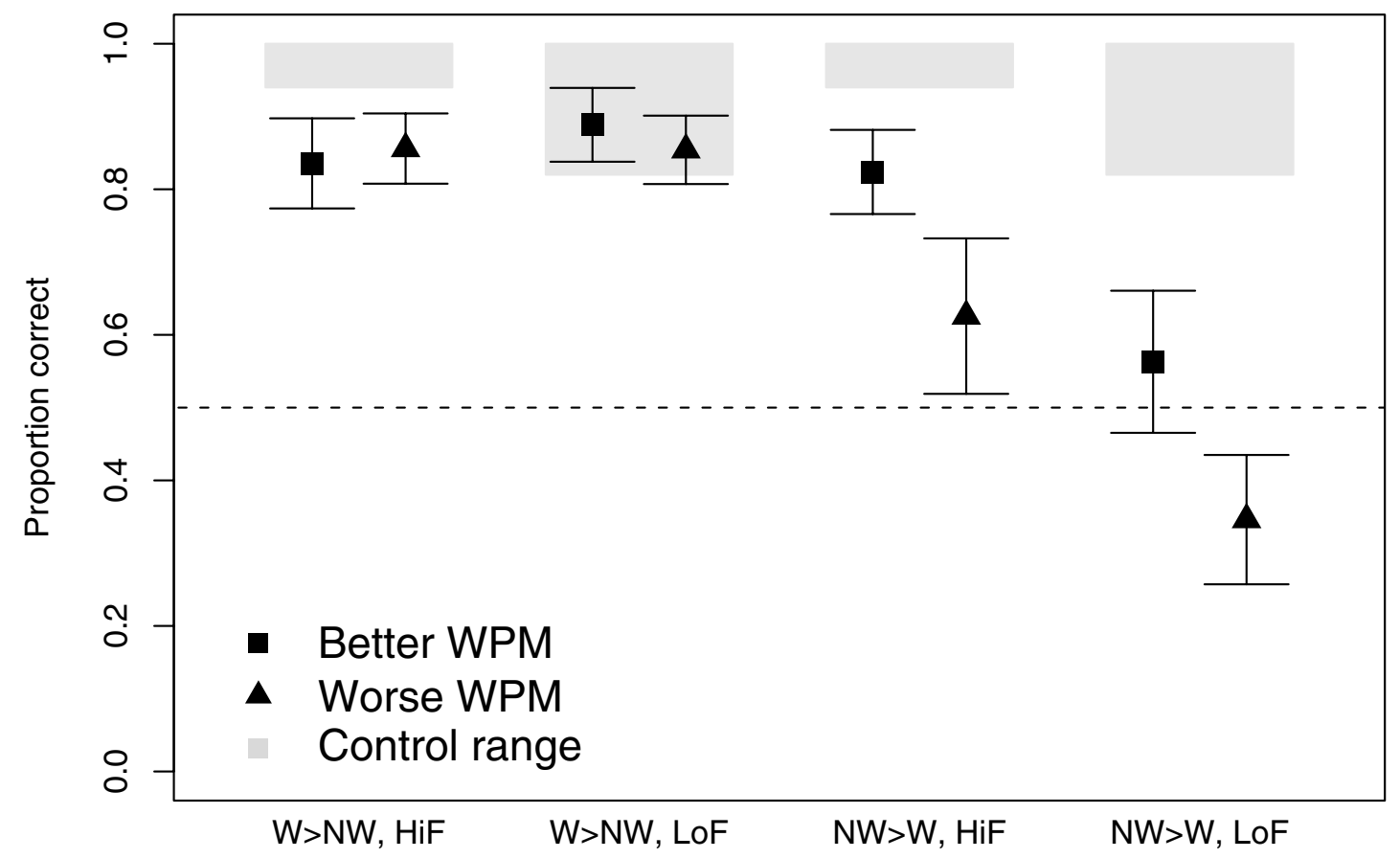

Figure 3. Performance on the OWT for each of the four subsets of materials, separately for the SD patients with milder comprehension impairment (as measured by Word-Picture Matching: "Better WPM" in the figure legend) and for those with more severe comprehension impairment ("Worse WPM"). Error bars are 95\% confidence intervals. The grey shading at the top indicates the range of control performance in the corresponding condition, and the dotted line at 0.5 on the $Y$ axis indicates chance performance.

and less impaired patients: the square plotted for $\mathrm{NW}>\mathrm{W}, \mathrm{HiF}$ in Figure 3). Either more severe semantic impairment (the triangle for $\mathrm{NW}>\mathrm{W}$, $\mathrm{HiF}$ ) or lower-frequency words (the square for $\mathrm{NW}>\mathrm{W}, \mathrm{LoF}$ ) reduced average performance near to chance level; and the combination of these two unfavourable factors (triangle for $\mathrm{NW}>\mathrm{W}, \mathrm{LoF}$ ) brought average performance below chance-i.e., under these conditions, the patients on average preferred the nonword to the word. These observations were further bolstered by an informal consideration of the data yielded by the four patients who were tested a second time, approximately 1 year after first assessment. Three of these four patients had lower scores on the second round of testing; but this difference was carried predominantly by $\mathrm{NW}>\mathrm{W}$ items, and within these items, was larger for low-frequency items (see Table 3).

To judge whether the performance reflected by the farthest-right triangle in Figure 3 was signifi- cantly below chance, indicating a reliable preference for the nonwords in this condition, we used the following logic. If a participant were simply responding at random to pairs in this (or any) condition, the likelihood of making 5 or fewer correct responses out of 18 is $p<.048$ from the binomial distribution; thus a score of 5 or less (proportion correct $\leq 0.28$ ) indicates that a participant's performance is likely to be below chance. Of the 13 patients with lower Word-Picture Matching values, 7/13 obtained a score of 5 or less in this $\mathrm{NW}>\mathrm{W}, \mathrm{LoF}$ condition. Furthermore, it is possible to calculate the exact likelihood that 7 or more patients out of 13 would achieve scores as low as these on the basis of chance responding alone. If the probability of a single patient making 5 or fewer correct responses is $p<.048$, then, from the binomial distribution, the likelihood of so many patients achieving such low scores by chance is $p<$ .0000008. It therefore seems reasonable to con- 
clude that, as a group, the SD patients with severe semantic deterioration did not just guess at random but reliably preferred the nonword to the word for condition $\mathrm{NW}>\mathrm{W}, \mathrm{LoF}$.

The same type of repeated-measures ANOVA that we employed for the SD group, when applied to the OWT performance of the Broca's aphasic patients, revealed no reliable main effect of condition, $\mathrm{W}>\mathrm{NW}$ vs. $\mathrm{NW}>\mathrm{W}, F(1,4)<1$; a significant main effect of word frequency, higher vs. lower, $F(1,4)=15.0, p<.02$; and no interaction between these two factors, $F(1,4)<1$.

It is notable that LD success on the OWT in both control participants and Broca's aphasics was affected by word frequency but not by orthographic typicality. This outcome supports our hypothesis that "natural selection" in word recognition-i.e., a dramatic preference for orthographically typical words - is an abnormal state of affairs engendered by reduced interaction between word meaning and orthographic analysis. As displayed in Figure 3, the fact that lower-frequency words yielded not only a lower mean but also a wider range of performance in control participants means that average SD performance on the $\mathrm{W}>\mathrm{NW}$, LoF subset was actually within control bounds. This outcome supports our claim that LD ability in semantically impaired patients can appear to be normal-if and only if the words are more orthographically typical than the nonword stimuli.

\section{EXPERIMENT 2: OBJECT DECISION: THE OVER-REGULAR OBJECT TEST (OOT)}

\section{Methods}

\section{Participants}

Ten patients with a clinical diagnosis of semantic dementia (defined as above), plus 10 age- and education-matched controls, participated in this experiment. Nine of the 10 patients had also participated in Experiment 1 (the OWT). Five of the 10 were from the Cambridge cohort and the other 5 (including 1 who had not participated in
Table 4. Background data for the OOT participants with semantic dementia, including each patient's sex, age, Mini-Mental State Exam score at (or very close to) the time of experimental testing, Word-Picture Matching as an assessment of comprehension, Object Naming as an assessment of semantic knowledge and word production, and score on copying the complex Rey figure as a measure of visuo-perceptual ability

\begin{tabular}{lcccccc}
\hline Patient & Sex & Age & MMSE & $\begin{array}{c}\text { Word-Pic } \\
\text { Match }^{a}\end{array}$ & $\begin{array}{c}\text { Object } \\
\text { Naming }\end{array}$ & $\begin{array}{c}\text { Rey } \\
\text { Copy }^{c}\end{array}$ \\
\hline AN & M & 64 & 29 & .98 & .91 & 36 \\
DV & M & 64 & 21 & .77 & .27 & 35 \\
NS & F & 69 & 25 & .66 & .13 & 36 \\
BS & M & 68 & 25 & .63 & .45 & 33 \\
EK & F & 60 & 26 & .61 & .27 & 36 \\
KI & M & 65 & 23 & .56 & .23 & 35 \\
JTw & M & 66 & 25 & .53 & .08 & 34 \\
ATe & M & 67 & 24 & .45 & .08 & 36 \\
JG & F & 70 & 19 & .17 & .03 & 34 \\
MK & F & 67 & 8 & .17 & .05 & 35 \\
\hline
\end{tabular}

a Score /30. ${ }^{\mathrm{b}}$ Proportion correct /64. ${ }^{\mathrm{c}}$ Score /36.

Experiment 1) were from the Bath cohort. Table 4 gives background data for the OOT participants, ordered by their comprehension scores (from highest to lowest) in word-picture matching. The measures in Table 4 are the same as those in Table 1 for the OWT patients, except that the reading measure has been replaced by scores on the test of copying the complex Rey Figure. As with reading regular words as a "control" task for the early processing component of lexical decision in Experiment 1, Rey scores are included for participants in the Object Decision experiment to establish thatshould our prediction of OD impairments be supported by the findings - this will not be attributable to any early visual perceptual deficits: All patients performed well within control limits in perceiving and indeed reproducing this complicated, meaningless figure.

\section{Stimulus materials}

We constructed a $2 \mathrm{AFC}$ visual object decision test dubbed the Over-regular Object Test (OOT). The test has two conditions, with 30 pairs of items in each condition; each pair contains one line drawing of a real object and one line drawing of a chimeric nonreal version of the same object. As a precise 
ROGERS ET AL.

parallel to the OWT in Experiment 1, where the conditions varied in orthographic typicality, the critical difference between the two conditions of the OOT is in the typicality of the real object relative to its nonobject mate: in half the pairs, the real object was more typical than the nonreal object $(\mathrm{R}>\mathrm{NR})$, and in the remaining half this relationship was reversed $(\mathrm{NR}>\mathrm{R})$. There is no completely objective measure of typicality in the sphere of visual object structure, as was available for orthographic structure in Experiment 1 in the form of bigram and trigram frequencies; but we can at least explain that by typicality here, we refer to the extent to which an object consists of parts that are shared by many other items in the same semantic category. Stimulus items are listed and described in Appendix B.

Typicality can arise either from having a feature in common with most other similar objects or from not having an unusual feature that occurs in very few objects in the category. For example, most familiar animals have modest-sized ears, and one can construct two pairs of items in which the unusual feature of large ears is associated with the real object in one case and with the nonreal object in the other. In the OOT, the former consisted of a line drawing of an elephant with large ears (R) paired with a false elephant with ears scaled down to normal size (NR); this pair then belongs to the $\mathrm{NR}>\mathrm{R}$ condition, because the nonreal elephant with smaller ears is more typical of the animal domain. Included in the $\mathrm{R}>\mathrm{NR}$ condition were a real and a chimeric monkey, the real one having normal monkey-sized ears and the false one having large elephant-sized ears; thus for these items, the animal with the more typical appearance is also the real animal. These two pairs of items are illustrated in Figure 4. In the nonanimal
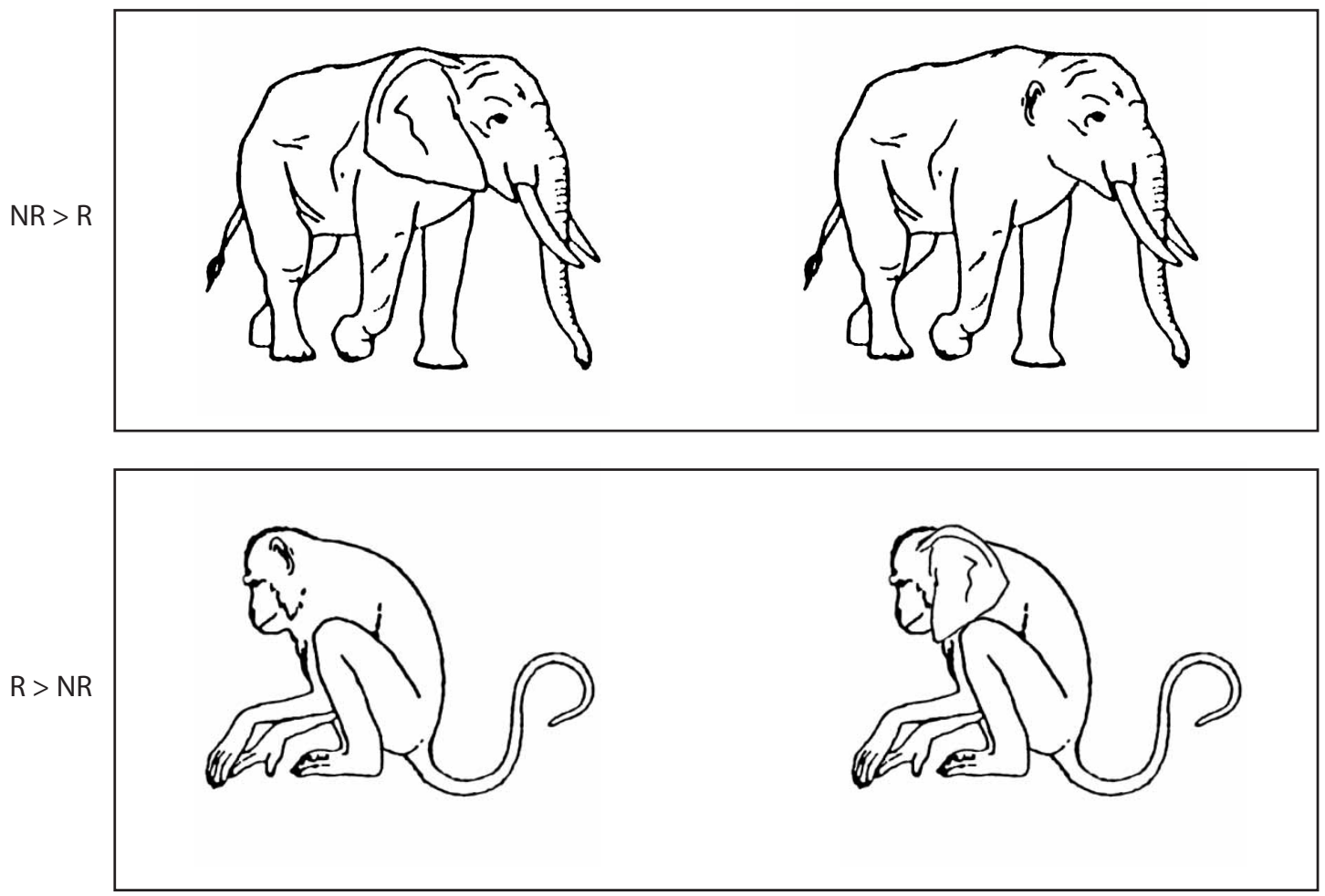

Figure 4. Examples of stimulus pairs from the $N R>R$ (Nonreal $>$ Real) and $R>N R$ (Real $>$ Nonreal) conditions of the OOT object decision test. 
domain, many tools have a straight, solid handle like the one on a typical screwdriver, but a spanner (wrench in American tool-speak) has an atypical open handle that fits around a nut. In the OOT, two pairs built round this feature were a screwdriver with a straight, solid handle vs. a screwdriver with a handle sporting a spanner-like hole $(R>N R)$, and a spanner with its normal (but domain-atypical) open handle vs. a spanner with a solid screwdriver-like handle $(\mathrm{NR}>\mathrm{R})$. We verified our own intuitions about the typicality of such features by asking 10 normal control participants to judge which version of a feature - verbally described-is more typical of objects in the relevant category, e.g., "Do animals typically have large or mediumsized ears?"; "Do animals typically have level or humped backs?"; "Do tools usually have hollow or solid handles?", etc. Their averaged judgments matched our intuitions in all instances.

We have already published data (Rogers et al., 2003) on the performance of SD patients on an Object Decision task designed along these principles. We are introducing a new OD test with additional SD data here for three reasons. First, the previous test, called the OAT (Over-regular Animal Test) contained, as its name suggests, only animals. Although this restriction was employed for a good reason-i.e., that living things have a better-defined typicality structure than manmade artefacts - it nevertheless seemed worthwhile to test the applicability of this principle to the large domain of artefacts as well. Secondly, there were a few "rogue" items in the OAT on which control participants often performed poorly (e.g., many of them preferred the gorilla with a tail to the real, tail-less gorilla: normal people are not entirely immune to typicality!), making it hard to conclude that the patients' preference for the nonobject in these few specific $\mathrm{NR}>\mathrm{R}$ pairs was abnormal. The items in the OOT are a better selection in this regard: out of 10 normal participants, 9 performed perfectly (100\% correct choices), and 1 control made one error in each condition (i.e., one error to a $\mathrm{R}>\mathrm{NR}$ item and one to a $\mathrm{NR}>\mathrm{R}$ item). Third, the OAT included just 16 pairs per condition, which somewhat limited our power to determine whether individual performance was reliably better or worse than chance. The OOT has 30 pairs/ condition.

Familiarity ratings from UK subjects (Morrison, Chappell, \& Ellis, 1997) were available for 53 of the 60 items in the OOT, and we collected ratings for the remaining 7 items. On this basis, we divided the 30 pairs in each condition $(\mathrm{R}>\mathrm{NR}$ and $\mathrm{NR}>\mathrm{R}$ ) into 15 higher- and 15 lowerfamiliarity items, just as we had done with regard to word frequency for the OWT in Experiment 1. Mean familiarity ratings (on a 5-point scale) for the high-familiarity items were 3.3 in the $\mathrm{R}>\mathrm{NR}$ condition and 3.1 in the $\mathrm{NR}>\mathrm{R}$ condition; for low-familiarity items, the mean ratings were 1.8 in the $\mathrm{R}>\mathrm{NR}$ condition and 1.9 in the $\mathrm{NR}>\mathrm{R}$ condition.

\section{Procedure}

The 60 experimental pairs of line drawings were each printed on a separate sheet of paper, with the real object on the left in half of the pairs and on the right in the remaining half, counterbalanced for condition. The order of list presentation was randomised, with the sole restriction being that two different pairs of items involving manipulation of the same feature, such as ear size, did not appear in close proximity. The instruction to participants was "Please point to the real thing." In case of potential problems in comprehension of instructions by the SD patients, presentation of the 60 test pairs was preceded by 3 very easy practice pairs of real and nonreal objects. None of the patients, even the most severely impaired, had difficulty following the instructions. Each pair of line drawings in the test consisted of a real and a nonreal version of the same object, and the difference between the two might not always be instantly apparent. In order to ensure that each participant noticed the difference, for each item in the test the experimenter always said (pointing to the relevant feature or part such as the ears on the two elephants or monkeys) "This one looks like this but this one looks like this - which do you think is the real one?", thus drawing the subject's attention to the difference without mentioning the name of the object or the relevant part or giving any specific information about them. 
ROGERS ET AL.

\section{Results and interim discussion}

Table 5 provides individual OOT scores (proportion correct out of 15) for the four stimulus subsets created by crossing OOT condition ( $\mathrm{R}>\mathrm{NR}$ vs. $\mathrm{NR}>\mathrm{R}$ ) with object familiarity (higher vs. lower) for each of the $10 \mathrm{SD}$ patients, followed by mean scores. As in Table 4, the patients are ordered by their scores, from highest to lowest, on the wordto-picture matching task from our semantic battery as a measure of degree of semantic deficit. Figure 5 displays the OOT results for the SD patients by condition on all items and also split by higher- vs. lower-familiarity objects. A repeatedmeasures ANOVA on these results yielded a significant main effect of condition, $\mathrm{R}>\mathrm{NR}$ vs. $\mathrm{NR}>\mathrm{R}, F(1,9)=25.3, p<.001$; a significant main effect of item familiarity, higher vs. lower, $F(1,9)$ $=13.7, p<.005$; and most importantly, a significant interaction between these two factors, $F(1,9)$ $=32.6, p<.001$.

To determine how the severity of semantic impairment interacts with the effects described above, we again added this factor (milder vs. more severe impairment, as assessed by a median split on word-picture matching) to the repeated-measures ANOVA described above. As before, the main

Table 5. OOT performance (proportion correct out of 15) for each of the four subsets of OOT stimulus pairs, for each of 10 patients with semantic dementia, ordered by the patients' scores on a test of WordPicture Matching (see Table 3), followed by mean proportions correct for the SD cases

\begin{tabular}{lccccc}
\hline & \multicolumn{2}{c}{$R>N R$} & & \multicolumn{2}{c}{$N R>R$} \\
\cline { 2 - 3 } \cline { 5 - 6 } Patient & $\begin{array}{c}\text { Higher } \\
\text { fam }\end{array}$ & $\begin{array}{c}\text { Lower } \\
\text { fam }\end{array}$ & & $\begin{array}{c}\text { Higher } \\
\text { fam }\end{array}$ & $\begin{array}{c}\text { Lower } \\
\text { fam }\end{array}$ \\
\hline AN & 1.00 & 1.00 & & .93 & .93 \\
DV & 1.00 & 1.00 & & .93 & .80 \\
EK & 1.00 & 1.00 & & .67 & .60 \\
NS & .87 & .80 & & .93 & .67 \\
BS & .87 & .87 & & .73 & .47 \\
KI & .80 & .93 & & .33 & .13 \\
JTw & .93 & 1.00 & & .47 & .40 \\
Ate & 1.00 & 1.00 & & .80 & .60 \\
JG & .93 & 1.00 & & .60 & .47 \\
MK & .93 & .93 & & .53 & .27 \\
Mean & .93 & .95 & & .69 & .53 \\
\hline
\end{tabular}

effects of familiarity, $F(1,8)=12.6, p<.01$, and stimulus type, $F(1,8)=38.4, p<.001$, were reliable, as was their interaction, $F(1,8)=61.3, p<$ .001 . The main effect of severity was also significant, $F(1,8)=5.3, p<.05$, but did not interact reliably with word frequency, $F(1,8)<1$, or stimulus type, $F(1,8)=2.6$, n.s. The three-way interaction was statistically reliable, $F(1,8)=$ 13.8, $p<.001$, indicating that the magnitude of the familiarity-by-regularity interaction itself varied reliably with the severity of the semantic impairment.

Figure 6 displays the OOT results as mean proportions correct, with $95 \%$ confidence intervals, on the four OOT stimulus subsets but also divided into two SD severity subgroups: OOT performance associated with the five best scores on the WPM task (range 0.98-0.61) vs. those associated with the five worst WPM scores (range 0.56$0.17)$. Just as was the case with the OWT results in Figure 3, the OOT results in Figure 6 are simple to describe and constitute an excellent match to our prediction for OD performance in semantically impaired patients. So long as the typicality (with respect to the category to which this object belongs, such as tools or vehicles, or birds or fourlegged animals) of the visuospatial structure in an OOT pair was greater for the real object than for its chimeric nonobject counterpart $(\mathrm{R}>\mathrm{NR})$, performance was good (though a little below the ceiling-level performance of the control subjects for higher-familiarity objects) and insensitive to both stimulus familiarity and degree of the patients' semantic degradation. When the nonreal members of the pairs were more typical of their object domains than the real things, on the other hand, OOT scores were high only when the two other factors affecting performance (stimulus familiarity and patient severity) were favourable (higher-familiarity objects and less impaired patients: the square plotted for $\mathrm{NR}>\mathrm{R}, \mathrm{HiF}$ in Figure 6). Either more severe semantic impairment (the triangle for $\mathrm{NR}>\mathrm{R}, \mathrm{HiF}$ ) or less familiar objects (the square for $\mathrm{NR}>\mathrm{R}, \mathrm{LoF}$ ) reduced average performance near to chance level; and the combination of these two unfavourable factors (triangle for $\mathrm{NR}>\mathrm{R}, \mathrm{LoF}$ ) brought average perform- 

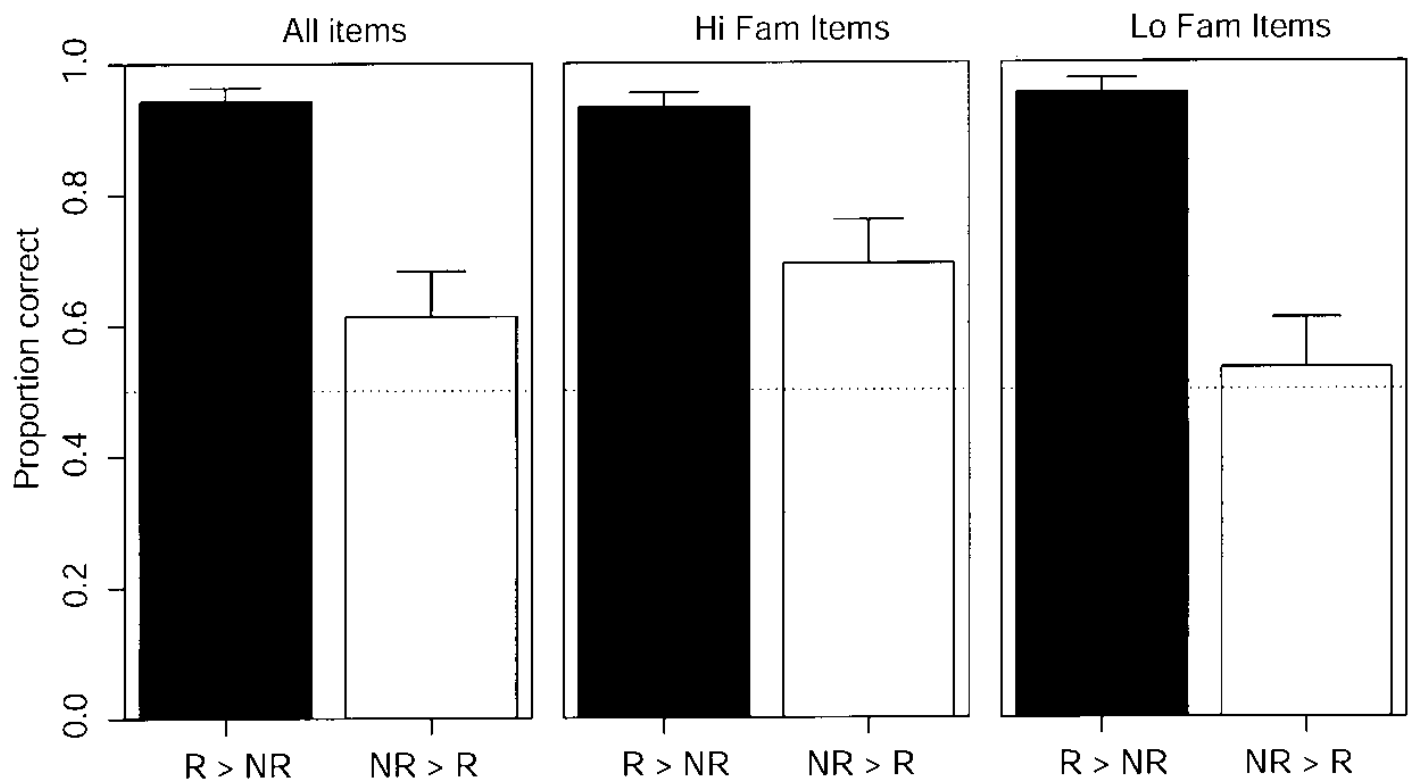

Figure 5. Average performance for the patients with semantic dementia on the OOT, first as a contrast between all items in each condition $(R>N R$ and $N R>R)$ and then divided into higher-and lower-familiarity object targets. The fine dotted line at 0.5 on the $Y$ axis indicates chance performance. Error bars indicate standard error of the mean.

ance below chance-i.e., under these conditions, the patients on average preferred the chimera to the real object.

We employed the same logic here as in the OWT study to determine whether the performance reflected by the farthest-right triangle in Figure 6 was significantly below chance, indicating a reliable preference for the nonobjects in this condition; note, however, that with a smaller $\mathrm{N}$ for both subjects and items in the OOT than the OWT, there is less power to judge this issue. From the binomial distribution, the likelihood of any individual making 4 or fewer correct responses (out of 15) on the basis of random guessing is $p<$ .06. Of the five patients with lower Word-Picture Matching values, 2/5 obtained a score of 4 or less in this $\mathrm{NR}>\mathrm{R}, \mathrm{LoF}$ condition; the probability of this occurring by chance alone is $p<.03$. Once again, therefore, it appears that the SD patients with severe semantic deterioration reliably preferred the nonreal chimera to the real object when the typicality relation was $N R>R$ and the object was in the lower half of the familiarity distribution.

A further two-factor repeated-measures ANOVA was performed to determine whether there might be any (unpredicted) impact of semantic domain - artefacts vs living things - in OOT performance. There was not: Condition, $F(1,8)=$ 20.7, $p<.002$; Domain, $F(1,8)<1$; Condition $\times$ Domain interaction, $F(1,8)<1$.

And finally, for the $N=9$ patients who performed both OWT and OOT experiments, we contrasted performance on the two tests. There was, as expected, a highly reliable effect of condition $(\mathrm{W}>\mathrm{NW}$ and $\mathrm{R}>\mathrm{NR}$ vs. $\mathrm{NW}>\mathrm{W}$ and $\mathrm{NR}>\mathrm{R})$, $F(1,8)=31.3, p<.001$; and there was a marginally significant effect of test, $F(1,8)=4.7, p=.063$, reflecting slightly higher scores on the OOT than the OWT. Crucially, however, there was not even a hint of an interaction between condition and test, $F(1,8)=0.001$ (yes, that is the $F$-value, not the $p$-value), $p=.97$. This lack of interaction will be obvious from contrasting Figures 2 and 5, or 3 and 
ROGERS ET AL.

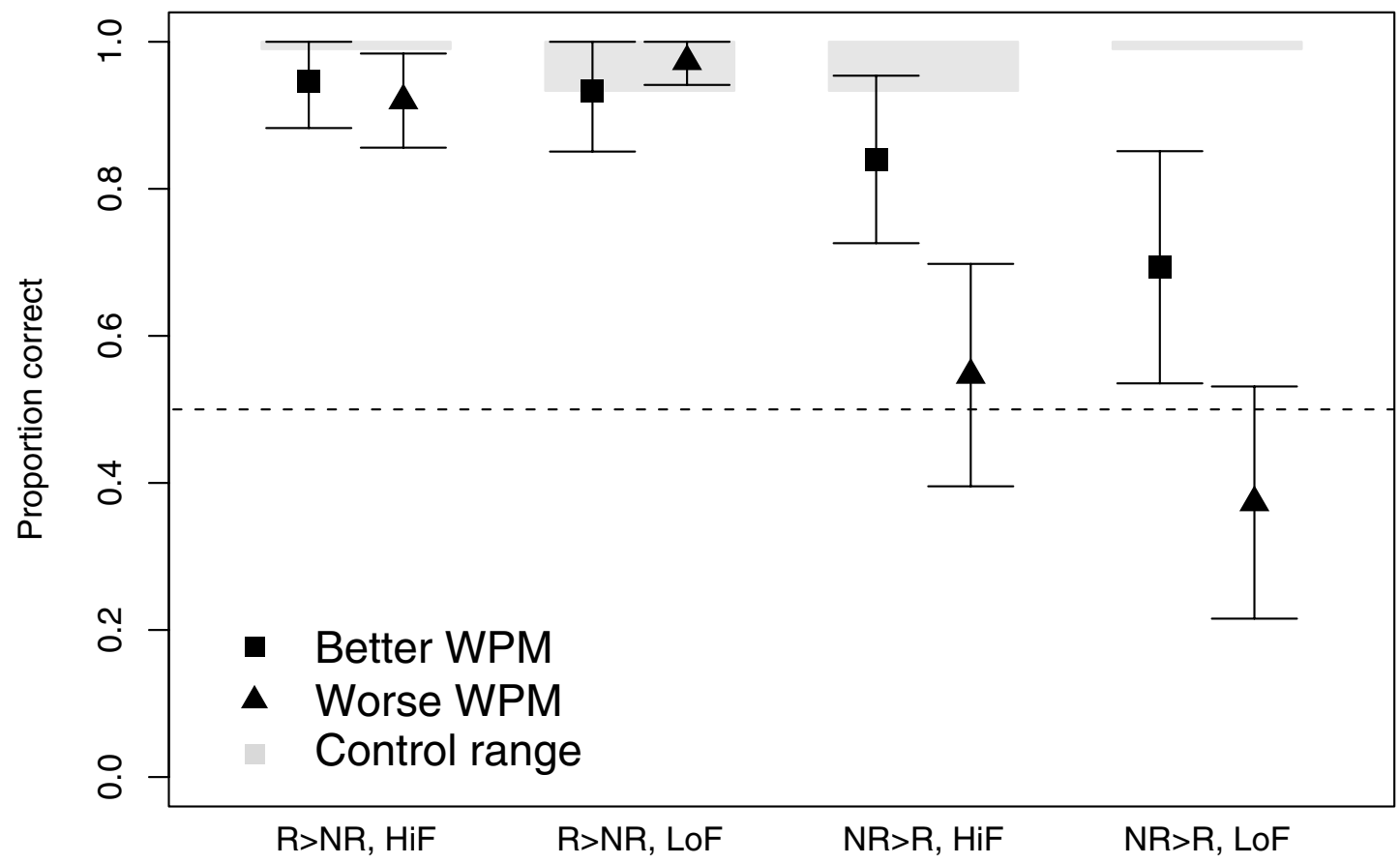

Figure 6. Performance on the OOT for each of the four subsets of materials, separately for the SD patients with milder comprehension impairment (as measured by Word-Picture Matching: "Better WPM" in the figure legend) and for those with more severe comprehension impairment ("Worse WPM"). The grey shading at the top indicates the range of control performance in the corresponding condition, and the dotted line at 0.5 on the $Y$ axis indicates chance performance.

6: The patterns of effects in these LD and OD experiments were strikingly identical.

The dramatic interaction between typicality and familiarity characterising the patients' OOT performance is perhaps even more impressive than the same phenomenon for the OWT, for the following reason. Although some of the $\mathrm{SD}$ patients in our cohort were highly educated (e.g., one had a PhD, a number had undergraduate degrees), one could worry that at least some patients might never have known the lower-familiarity words in the OWT like tryst, and that for such items it might be natural to prefer a more typical spelling like trist. Of course we attempted to deal with this issue by having control participants who were not only agebut also education-matched to the patients, and we hope that this has been satisfactory. We are also, however, reassured by obtaining precisely the same pattern of performance in the OOT, wherealthough the objects can readily be divided into more and less familiar subsets-objects in the lower-familiarity subset (such as wagon or penguin) would surely have been known to every patient premorbidly.

\section{GENERAL DISCUSSION}

We started this investigation with the question of whether word and/or object recognition can be normal in patients whose early structural processing of words and pictures is relatively intact but whose semantic knowledge about the concepts represented by such words and pictures is degraded. Empirically, we have established that this question cannot be answered without a 
detailed description of the stimulus materials used to test recognition (see Hovius, Kellenbach, Graham, Hodges, \& Patterson, 2003, for a similar argument). As previously demonstrated in two single case studies (Bub et al., 1985; Diesfeldt, 1992), accuracy of word recognition as measured by lexical decision can range from normal to chance level depending on the stimuli; and the same is true of object recognition as measured by object decision (Rogers et al., 2003). It is now possible to provide a clear statement of one set of stimulus conditions under which the performance of semantically impaired individuals in these tests may approximate to normal, and of the kinds of changes to these stimulus conditions that will depress the patients' success to a level that is moderately abnormal, or severely impaired, or indeed significantly below chance. If the real words or objects are typical of their domains (which in the case of written words means that they are composed of typical, common letter sequences, and in the case of objects means that their visual features are mostly typical of their categories) and the nonreal words or objects are constructed to have atypical characteristics (conditions $\mathrm{W}>\mathrm{NW}$ in Experiment 1 and $\mathrm{R}>\mathrm{NR}$ in Experiment 2), then the patients will mainly choose the real words/objects and appear to have normal recognition despite degraded semantics. If the typicality relations of the real vs. nonreal stimuli are reversed, however (conditions $\mathrm{NW}>\mathrm{W}$ and $\mathrm{NR}>\mathrm{R}$ ), then the patients' performance will be abnormal. The degree to which their accuracy departs from normal then depends on two further factors: the frequency or familiarity of the real word or object, and the extent of the patient's semantic deficit. If both of these factors are favourable (words/objects of high frequency/familiarity, mild semantic impairment), then performance can still be near normal. If one of these factors is auspicious and the other inauspicious, then performance will be markedly impaired and perhaps even fall to near chance. If both factors are detrimental, then performance may well be significantly below chancethat is, the patient will actually prefer the typical nonword or nonobject to the atypical real word or real object.
The conclusions that we draw from this pattern of results are (a) that normal recognition depends on, and indeed is a direct product of, the interaction of perceptual and conceptual processing; and therefore (b) that a degraded semantic system will inevitably impair the ability to "know" a letter string or object-like representation as belonging to the repertoire of real words or objects. It is important to emphasise that, in this conception, the good performance observed when the real stimulus is more typical than the made-up one does not mean that recognition is normal under these conditions. Low accuracy to $\mathrm{NW}>\mathrm{W}$ or $\mathrm{NR}>\mathrm{R}$ reflects a perceptual recognition system operating without normal benefit of interaction with semantic knowledge, resulting in "natural selection"; but so does high accuracy to $\mathrm{W}>\mathrm{NW}$ or $\mathrm{R}>\mathrm{NR}$. As demonstrated in a whole host of studies of semantic dementia (e.g., Hodges, Graham, \& Patterson, 1995; Rogers et al., in press; Saffran \& Schwartz, 1994; Schwartz, Marin, \& Saffran, 1979; Warrington, 1975), the hallmark of semantic degradation is a frequency-modulated whittling away of detailed, specific knowledge and a relative preservation of robust information that characterises whole batches of other similar things. In one of our favourite anecdotes demonstrating this point, an SD patient in our cohort looked at a picture of a zebra and said "It's a horse, isn't it?". Then, pointing to the stripes, she added "What are these funny things for?"

Prior to the present study and a very few others in a similar vein (e.g., the beautiful early studies of an SD patient by Schwartz et al., 1979, which included tasks like object name recognition), most of the evidence that semantic degradation has this particular impact (i.e., dissolution of detail, especially for less familiar words/objects) has come from studies of response production, such as object naming (Hodges et al., 1995), word or picture sorting (Rogers et al., in press), concept definitions (Lambon Ralph, Graham, Patterson, \& Hodges, 1999), object use (Bozeat, Lambon Ralph, Patterson, \& Hodges, 2002), and so on. The current line of research extends this impact into the domain of recognition, and not recognition in the taxing sense of identifying a word or object by naming or 
defining it, but simply recognition in the sense of “yes, I know this to be a real, familiar thing." In another of our favourite anecdotes (this one from an SD patient studied by M. L. Gorno-Tempini, personal communication), the patient-who was being asked to perform lexical decisions_-objected to the test with the query "How can I say whether it's real if I don't know what it means?"

One of our colleagues in Cambridge (A. Marcel, personal communication) is wont to challenge our view of the critical role of conceptual knowledge in object recognition, naming, etc., by pointing out that, although he has no "conceptual" knowledge of a tulip other than what it looks like, he can easily recognise and name it. Our response to this point is simply that his conceptual knowledge of the tulip manifests itself in his ability to produce the name "tulip" when confronted with one, or to draw a sketch of a tulip when given its name. This knowledge is encoded in the network of connections and hidden units that intermediate among visual representations of objects and phonological representations of spoken words (as well as representations in other modalities). Different individual objects or classes of objects have more or less rich and extensive networks of modality-specific information content; and most people (other than flower experts) probably know little about tulips apart from what they look like and what they are called, but much more about the things that they deal with every day, such as trousers or coffee or mobile telephones. But no matter how many different modalities (visual, auditory, tactile, olfactory, verbal: Allport, 1985; Saffran, 2000; Saffran \& Schwartz, 1994) represent specific knowledge about a particular concept, our claim is that the function of the semantic system in the brain is to orchestrate the interactions amongst these modality-specific representations; and that this function-crucially-is subserved by modality-independent representations, that allow all of the modality-specific information to communicate and combine so that we can recognise real-world stimuli from many different input modalities and respond to them in many different output modes (see Rogers et al., 2003, in press, for detailed description). Whether the various interacting modality-specific representations are themselves best understood as "perceptual" or as "semantic" may be a bone of contention amongst some theorists; but it is not clear to us that any serious theoretical issues hinge upon this distinction.

Our position is in line with a view that is coming to permeate several different subdisciplines of cognitive psyschology, including cognitive development (e.g., Mareschal, 2000; Quinn, 2002; Smith \& Samuelson, 1997), visual cognition and expertise in normal adults (e.g., Barsalou, 2003; Tarr \& Gauthier, 2000), and categorylearning (e.g., Goldstone, Lippa, \& Shiffrin, 2001), as well as cognitive neuropsychology: Specifically, that perceiving, recognising, knowing, and remembering constitute mutually interdependent and highly interactive processes, rather than functionally separable and independent cognitive modules. In this vein it is worth briefly mentioning the elegant experiments of Arguin, Bub, Dixon, and colleagues, which provide compelling evidence for the interactive nature of perception and conception (Arguin, Bub, \& Dudek, 1996; Dixon, Bub, \& Arguin, 1997, 1998). Patient ELM was a visual agnosic who appeared to show particular difficulty in recognising living things from vision, despite normal semantic knowledge about these items in other modalities. ELM's visual impairment extended to the discrimination of simple blob-shapes varying in more than one spatial dimension; but this deficit was dramatically attenuated when ELM learned to associate the blobs with a set of realworld concepts that were semantically unrelated to one another. When taught to associate the same blobs with a set of closely related real-world concepts, ELM showed no benefit. Similar results have been achieved for face recognition in ELM (Dixon et al., 1998), and even for perceptual discrimination in healthy control subjects (Dixon et al., 1997; Gauthier, James, Curby, \& Tarr, 2003). The results suggest that semantic knowledge can influence not only the recognition of familiar realworld objects (as in the current study), but also the visual discrimination of simple, novel shapes. These and other studies cited above lead us to 
agree with the comments of Smith (2000, p. 96), drawn from a complementary literature on the study of conceptual development, who writes:

The agenda for continued progress, then, is the study of the dynamics of perceiving and remembering over multiple time scales, how they combine to make a moment of knowing that is fit to the idiosyncracies of the here and now, continuous with the just previous past, and wisely informed by a lifetime of perceiving and remembering.

In summary, we predicted-on the basis of a detailed and indeed implemented model of semantic memory - that the consequence of degraded conceptual knowledge in the sphere of word and object recognition would be impaired performance with the specific characteristic of a dramatic preference for typicality, modulated by both item familiarity and degree of semantic deficit. The performance of large-ish groups of patients with semantic dementia in tests of both lexical decision and object decision demonstrated precisely this predicted tendency to select "natural" rather than "real" objects and words.

\section{REFERENCES}

Allport, D. A. (1985). Distributed memory, modular systems and dysphasia. In S. K. Newman \& R. Epstein (Eds.), Current perspectives in dysphasia (pp. 32-60). Edinburgh: Churchill Livingstone.

Arguin, M., Bub, D., \& Dudek, G. (1996). Shape integration for visual object recognition and its implication for category-specific visual agnosia. Visual Cognition, 3, 221-275.

Barsalou, L. W. (2003). Situated simulation in the human conceptual system. Language and Cognitive Processes, 18, 513-562.

Behrmann, M., \& Bub, D. (1992). Surface dyslexia and dysgraphia: Dual routes, single lexicon. Cognitive Neuropsychology, 9, 209-251.

Bozeat, S., Lambon Ralph, M. A., Graham, K. S., Patterson, K., Wilkin, H., Rowland, J., Rogers, T. T., \& Hodges, J. R. (2003). A duck with 4 legs: Investigating the structure of conceptual knowledge using picture drawing in semantic dementia. Cognitive Neuropsychology, 20, 27-47.

Bozeat, S., Lambon Ralph, M. A., Patterson, K., Garrard, P., \& Hodges, J. R. (2000). Nonverbal semantic impairment in semantic dementia. Neuropsychologia, 38, 1207-1215.

Bozeat, S., Lambon Ralph, M. A., Patterson, K., \& Hodges, J. R. (2002). When objects lose their meaning: What happens to their use? Cognitive, Affective and Behavioral Neurosciences, 2, 236-251.

Breedin, S. D., Saffran, E. M., \& Coslett, H. B. (1994). Reversal of the concreteness effect in a patient with semantic dementia. Cognitive Neuropsychology, 11, 617-660.

Bub, D., Black, S., Hampson, E., \& Kertesz, A. (1988). Semantic encoding of pictures and words: Some neuropsychological observations. Cognitive Neuropsychology, 5, 27-66.

Bub, D., Cancelliere, A., \& Kertesz, A. (1985). Wholeword and analytic translation of spelling to sound in a nonsemantic reader. In K. Patterson, J. C. Marshall, \& M. Coltheart (Eds.), Surface dyslexia (pp.15-34). Hove, UK: Lawrence Erlbaum Associates Ltd.

Diesfeldt, H. F. A. (1992). Impaired and preserved semantic memory functioning in dementia. In L. Backman (Ed.), Memory functioning in dementia (pp. 227-263). Amsterdam: Elsevier.

Dixon, M., Bub, D., \& Arguin, M. (1997). The interaction of object form and object meaning in the identification performance of a patient with categoryspecific visual agnosia. Cognitive Neuropsychology, 14, 1085-1130.

Dixon, M., Bub, D., \& Arguin, M. (1998). Semantic and visual determinants of face recognition in a prosopagnosic patient. Journal of Cognitive Neuroscience, 10, 362-376.

Gauthier, I., James, T. W., Curby, K. W., \& Tarr, M. J. (2003). The influence of conceptual knowledge on visual discrimination. Cognitive Neuropsychology, 20, 507-523.

Gloor, P. (1997). The temporal lobe and limbic system. New York/Oxford: OUP.

Goldstone, R. L., Lippa, Y., \& Shiffrin, R. M. (2001). Altering object representations through category learning. Cognition, 78, 27-43.

Harley, T. A. (1995). The psychology of language: From data to theory. Hove, UK: Psychology Press.

Hodges, J. R., Graham, N. L., \& Patterson, K. (1995). Charting the progression in semantic dementia: Implications for the neural organisation of long-term memory. Memory, 3, 463-495.

Hodges, J. R., Patterson, K., Oxbury, S., \& Funnell, E. (1992). Semantic dementia: Progressive fluent aphasia with temporal lobe atrophy. Brain, 115, 1783-1806. 
Hovius, M., Kellenbach, M. L., Graham, K., Hodges, J. R., \& Patterson, K. (2003). What does the object decision task measure? Reflections on the basis of evidence from semantic dementia. Neuropsychology, 17, 100-107.

Humphreys, G. W., Riddoch, M. J., \& Quinlan, P. T. (1988). Cascade processes in picture identification. Cognitive Neuropsychology, 5, 67-103.

Kucera, H., \& Francis, W. N. (1967). Computational analysis of present-day American English. Providence, RI: Brown University Press.

Lambon Ralph, M. A., Graham, K. S., Patterson, K., \& Hodges, J. R. (1999). Is a picture worth a thousand words? Evidence from concept definitions by patients with semantic dementia. Brain and Language, 70, 309-335.

Lambon Ralph, M. A., \& Howard, D. (2000). Gogi aphasia or semantic dementia? Simulating and assessing poor verbal comprehension in a case of progressive fluent aphasia. Cognitive Neuropsychology, $17,437-465$.

Mareschal, D. (2000). Infant object knowledge: Current trends and controversies. Trends in Cognitive Science, 4, 408-416.

McClelland, J. L., \& Rogers, T. T. (2003). The Parallel Distributed Processing approach to semantic cognition. Nature Reviews Neuroscience, 4, 310-322.

Morrison, C. M., Chappell, T. D., \& Ellis, A. W. (1997). Age of acquisition norms for a large set of object names and their relation to adult estimates and other variables. Quarterly Journal of Experimental Psychology, 50A, 528-559.

Moss, H. E., Tyler, L. K., Hodges, J. R., \& Patterson, K. (1995). Exploring the loss of semantic memory in semantic dementia: Evidence from a primed monitoring study. Neuropsychology, 9, 16-26.

Patterson, K., \& Behrmann, M. (1997). Frequency and consistency effects in a pure surface dyslexic patient. Journal of Experimental Psychology: Human Perception and Performance, 23, 1217-1231.

Patterson, K., \& Hodges, J. R. (1992). Deterioration of word meaning: Implications for reading. Neuropsychologia, 30, 1025-1040.

Patterson, K., Suzuki, T., Wydell, T., \& Sasanuma, S. (1995). Progressive aphasia and surface alexia in Japanese. Neurocase, 1, 155-165.

Plaut, D. C. (1997). Structure and function in the lexical system: Insights from distributed models of word reading and lexical decision. Language and Cognitive Processes, 12, 765-805.
Plaut, D. C., McClelland, J. L., Seidenberg, M. S., \& Patterson, K. (1996). Understanding normal and impaired word reading: Computational principles in quasi-regular domains. Psychological Review, 103, 56-115.

Quinn, P. C. (2002). Early categorization: A new synthesis. In U. Goswami (Ed.), Blackwell handbook of child cognitive development (pp. 84-101). Oxford: Blackwell.

Riddoch, M. J., \& Humphreys, G. W. (1987). Visual object processing in optic aphasia: A case of semantic access agnosia. Cognitive Neuropsychology, 4, 131-185.

Rogers, T. T., Garrard, P., Lambon Ralph, M. A., Bozeat, S., Hodges, J. R., McClelland, J. L., \& Patterson, K. (in press). The structure and deterioration of semantic memory: A neuropsychological and computational investigation. Psychological Review.

Rogers, T. T., Hodges, J. R., Lambon Ralph, M. A., \& Patterson, K. (2003). Object recognition under semantic impairment: The effects of conceptual regularities on perceptual decisions. Language and Cognitive Processes, 18, 625-662.

Rogers, T. T., \& Plaut, D. C. (2002). Connectionist perspectives on category-specific deficits. In E. Forde \& G. Humphreys (Eds.), Category specificity in brain and mind (pp. 251-289). Hillsdale, NJ: Psychology Press.

Saffran, E. M. (2000). The organization of semantic memory: In support of a distributed model. Brain and Language, 71, 4-212.

Saffran, E. M., \& Schwartz, M. F. (1994). Of cabbages and things: Semantic memory from a neuropsychological perspective- a tutorial review. In C. Umiltà \& M. Moscovitch (Eds.), Attention and performance $X V$ (pp. 507-535). Hillsdale, NJ: Lawrence Erlbaum Associates Inc.

Schwartz, M. F., Marin, O. S. M., \& Saffran, E. M. (1979). Dissociations of language function in dementia: A case study. Brain and Language, 7, 277306.

Seidenberg, M. S., \& McClelland, J. L. (1989). A distributed, developmental model of word recognition and naming. Psychological Review, 96, 523-568.

Smith, L. B. (2000). From knowledge to knowing: Real progress in infant categorisation. Infancy, 1, 91-97.

Smith, L. B., \& Samuelson, L. K. (1997). Perceiving and remembering: Category stability, variability, and development. In K. Lamberts \& D. Shanks (Eds.), Knowledge, concepts, and categories (pp. 93-131). Hove, UK: Psychology Press. 
Snowden, J. S., Goulding, P. J., \& Neary, D. (1989). Semantic dementia: A form of circumscribed cerebral atrophy. Behavioural Neurology, 2, 111-138.

Tarr, M., \& Gauthier, I. (2000). FFA: A flexible fusiform area for subordinate-level visual processing automatized by expertize. Nature Neuroscience, 3, 754-769.

Tyler, L. K., \& Moss, H. E. (1998). Going, going, gone...? Implicit and explicit tests of conceptual knowledge in a longitudinal study of semantic dementia. Neuropsychologia, 36, 1313-1323.
Ward, J., Stott, R., \& Parkin, A. J. (2000). The role of semantics in reading and spelling: evidence for the "summation" hypothesis. Neuropsychologia, 38, 1643-1653.

Warrington, E. K. (1975). Selective impairment of semantic memory. Quarterly Journal of Experimental Psychology, 27, 635-657.

\section{APPENDIX A}

List of stimulus items in the OWT

\begin{tabular}{|c|c|c|c|c|c|c|c|}
\hline \multicolumn{4}{|c|}{ Higher frequency } & \multicolumn{4}{|c|}{ Lower frequency } \\
\hline \multicolumn{2}{|c|}{$W>N W$} & \multicolumn{2}{|c|}{$N W>W$} & \multicolumn{2}{|c|}{$W>N W$} & \multicolumn{2}{|c|}{$N W>W$} \\
\hline Target & Distractor & Target & Distractor & Target & Distractor & Target & Distractor \\
\hline drew & driew & view & vew & nod & knod & knob & nob \\
\hline nice & knice & knife & nife & amiss & amyss & abyss & abiss \\
\hline cheese & cheize & seize & seese & hum & humb & numb & num \\
\hline cope & coap & soap & sope & legion & legeon & pigeon & pigion \\
\hline pet & pebt & debt & det & grist & gryst & cyst & cist \\
\hline goat & ghot & ghost & goast & sneer & sneir & weir & weer \\
\hline dam & damb & lamb & lam & shrewd & shreud & feud & fewd \\
\hline rot & racht & yacht & yot & nab & gnab & gnash & nash \\
\hline soak & swoak & sword & sord & node & gnode & gnome & nome \\
\hline rim & rimb & $\operatorname{limb}$ & $\lim$ & rile & ruile & guile & gile \\
\hline garter & gartyr & martyr & marter & lackey & lhaki & khaki & kackey \\
\hline grease & griece & niece & nease & dollop & dolyp & polyp & pollop \\
\hline salve & psalve & psalm & salm & sine & scyne & scythe & sithe \\
\hline fossil & fausil & sausage & sossage & gist & gyst & tryst & trist \\
\hline vile & vaisle & aisle & ile & coffer & cophyr & zephyr & zeifer \\
\hline pall & pawl & drawl & drall & booth & beuth & sleuth & slooth \\
\hline bridal & bridyll & idyll & idal & graphic & grapphic & sapphire & saphire \\
\hline partake & partaque & opaque & opake & conscript & conscrypt & crypt & cript \\
\hline
\end{tabular}


ROGERS ET AL.

\section{APPENDIX B}

\section{List of stimulus items in the OOT}

\begin{tabular}{|c|c|c|c|}
\hline \multicolumn{2}{|r|}{$R>N R$} & \multicolumn{2}{|r|}{$N R>R$} \\
\hline Target & Chimera & Target & Chimera \\
\hline \multicolumn{4}{|c|}{ Higher familiarity } \\
\hline fork & fork w/ no handle & kettle & kettle w/ no spout \\
\hline table & table w/ piano lid added & scissors & scissors w/ straight handle \\
\hline lorry & lorry w/ train undercarriage & comb & comb w/ handle added \\
\hline clock & clock w/ spout added & train & train w/ lorry wheels \\
\hline bus & bus w/ no wheels & umbrella & umbrella handle w/ stick attached \\
\hline chisel & chisel w/ clothespin-handle & fish & fish w/ legs \\
\hline cow & cow w/ mane and long neck & grand piano & grand piano w/ lid removed \\
\hline sheep & sheep w/ seal flippers & bird & bird w/ pig head \\
\hline hammer & hammer w/ plier-handles & horse & horse w/ short neck and no mane \\
\hline racquet & racquet w/ umbrella handle & watering can & watering can w/ no spout \\
\hline screwdriver & screwdriver w/ spanner handle & rabbit & rabbit w/ short ears \\
\hline chicken & chicken w/ long neck & duck & duck w/ four legs \\
\hline mouse & mouse w/ long ears & spanner & spanner w/ screwdriver-handle \\
\hline squirrel & squirrel w/ webbed feet & rooster & rooster w/ four goat legs \\
\hline fox & fox w/ no ears & goose & goose w/ short neck \\
\hline \multicolumn{4}{|c|}{ Lower familiarity } \\
\hline drum & drum w/ spout added & frog & frog w/ squirrel feet \\
\hline pig & pig w/ bird head & pliers & pliers w/ straight handle \\
\hline axe & axe w/ scissor-handles & swan & swan w/ short neck \\
\hline monkey & monkey w/ elephant ears & seal & seal w/ sheep legs \\
\hline goat & goat w/ two chicken legs & elephant & elephant w/ small ears \\
\hline donkey & donkey w/ hump & turtle & turtle w/ ears added \\
\hline lion & lion w/ no tail & yacht & yacht w/ wheels added \\
\hline wagon & wagon w/ runners & eagle & eagle w/ ears added \\
\hline raccoon & raccoon $\mathrm{w} /$ no ears & helicopter & helicopter w/ wagon wheels \\
\hline deer & deer w/ six legs & penguin & penguin w/ kangaroo head \\
\hline leopard & leopard w/ long neck & clothespin & clothespin w/ handle added \\
\hline giraffe & giraffe w/ seahorse body & camel & camel w/ no hump \\
\hline kangaroo & kangaroo w/ penguin head & seahorse & seahorse w/ giraffe body \\
\hline zebra & zebra w/ rhino horn & rhino & rhino w/ no horn \\
\hline alligator & alligator w/ fins and no legs & ostrich & ostrich w/ tail added \\
\hline
\end{tabular}

